\title{
COMMUNICATIONS
}

\section{REACTION OF ANIMAL EYES TO SANGUINARINE AND ARGEMONE OIL*}

\author{
BY \\ GRAHAM C. DOBBIE $\dagger$ AND MAURICE E. LANGHAM $\ddagger$ \\ From the Institute of Ophthalmology, University of London
}

OuR interest in the reaction of the eye to the oil extracted from the seeds of Argemone mexicana and to the alkaloid sanguinarine (Fig. 1), a constituent of argemone oil, arose from the recent studies of several groups of investigators. Hakim (1954) observed that subconjunctival injections of either argemone oil or sanguinarine to rabbits and monkeys produced a marked rise in intra-ocular pressure, and he concluded from these and other studies that sanguinarine induced a glaucomatous condition in animals similar to open-angle glaucoma. Lieb and Scherf (1956) studied the effect of intravenous injections of sanguinarine and related alkaloids on the intra-ocular pressure of rabbits, and observed that a single injection of sanguinarine caused an ocular hypertension lasting 30 to 45 minutes. The authors suggested that the alkaloid acted on a pressure regulatory centre located in the central nervous system, and this view found experimental support in the communication of Hakim (1957) that a chronic ocular hypertension could be induced in conscious cats by periodic injections of very small quantities of sanguinarine into the lateral ventricles. Unfortunately, no detailed report on this latter study has yet been published. Finally, Leach and Lloyd (1956) reported that a chronic ocular hypertension in monkeys could be induced by prolonged feeding with sanguinarine, and Shevalev (1957) observed a glaucomatous-like condition in cats injected with argemone oil daily.

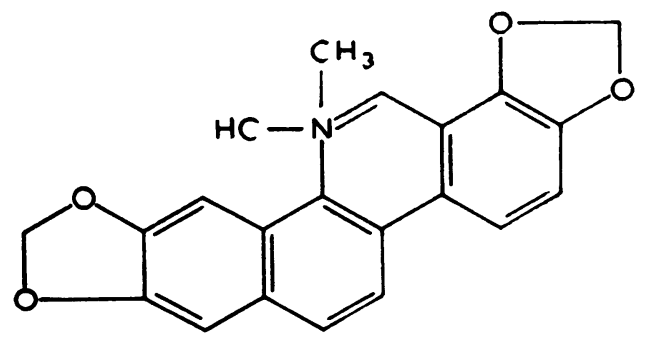

FIG. 1.-Chemical structure of the alkaloid sanguinarine $\left(\mathrm{C}_{20} \mathrm{H}_{15} \mathrm{NO}_{5}\right)$.

* Received for publication July 26, 1960.

+ The Retina Foundation, Boston, Massachusetts.

‡ The Wilmer Institute, Johns Hopkins Medical School, Baltimore 5, Maryland. 
The above studies relate closely to the clinical condition of epidemic dropsy which is now generally accepted to be due to contamination of cooking oils with argemone oil (Chopra, Pasricha, Goyal, Lal, and Sen, 1939; Lal, Das Gupta, Mukherji, and Adak, 1941; Meaker, 1951). Outbreaks of epidemic dropsy have been reported to be accompanied by a high incidence of glaucoma which closely resembles primary open-angle glaucoma (Maynard, 1909; Kirwan, 1934, 1936; Dutt, 1950).

The aim of this study was to elucidate the mechanism by which sanguinarine, injected either intravenously or intraventricularly, produced acute and chronic changes in intra-ocular pressure. In addition, it was hoped to establish whether the action of argemone oil in producing tissue oedema could be ascribed to the alkaloid sanguinarine.

\section{Methods}

Adult rabbits of the New Zealand white strain, weighing between 2 and $3 \mathrm{~kg}$., cats of 1 to $4 \mathrm{~kg}$., and hens of approximately $2 \mathrm{~kg}$. were used in this study. Rabbits were fed Diet 18 pellets (Associated London Flour Millers), water ad lib, and hay once a week. Cats were fed on a commercial cat food (Kit-e-Kat) and milk. Hens were fed standard layers mash, $4 \mathrm{oz}$. mixed corn and wheat daily, and water ad lib.

In manometric studies the intra-ocular and femoral arterial pressures were measured, using a Sanborn $150 \mathrm{M}$ rectilinear pen recorder and Sanborn 267 B pressure transducers following the technique described by Langham (1959). Tonometric studies were made with a standard Schiötz tonometer on conscious animals under topical 0.2 per cent. Novescine anaesthesia. Cats were cradled in the arms of one operator while a second took the readings; measurements on rabbits were made with the animals placed on their sides. Not all animals were suitable for these experiments and only those were selected which gave reproducible readings over a period of 2 to 3 days before experimentation. Cannulation of the left or right lateral cerebral ventricle was made following the technique of Feldberg and Sherwood (1953). Animals were left for 7 to 10 days post-operatively before experimentation.

Analysis.-Colorimetric and fluorescent methods for the quantitative determination of sanguinarine were developed.

The colorimetric method was based on the finding that sanguinarine in acid solution has an absorption peak at a wavelength of $455 \mathrm{~m} \mu$. At this wavelength the optical density of an acid solution of sanguinarine increased directly with concentrations from 0 to $1 \mathrm{mg}$. per cent. For the determination of sanguinarine in plasma, $1 \mathrm{ml}$. plasma was dissolved in $9 \mathrm{ml} .5 \mathrm{~N} \mathrm{HCl}$ solution. The optical transmission was read immediately against a plasma blank at a wavelength of $\mathbf{4 5 5}$ $\mathrm{m} \mu$ in a cuvette having a $3 \mathrm{~cm}$. light path. A concentration of $10 \mathrm{mg}$. sanguinarine/ $100 \mathrm{ml}$. gave an optical density reading of 0.45 under these conditions. Readings were taken on a Unicam SP. 600 spectrophotometer.

The fluorometric technique was developed for the determination of concentrations of sanguinarine below $1 \mathrm{mg}$. per cent. $1 \mathrm{ml}$. plasma was dissolved in $14 \mathrm{ml}$. 
$10 \mathrm{NHCl}$ solution and the fluorescence read against a plasma blank. The fluorescence was measured using a Phoenix light-scattering apparatus coupled to a Tinsley V.S. 6.4500 galvanometer. The Phoenix recorder has a mercury vapour light source and a 1P21 R.C.A. photomultiplier tube. For concentrations of 0 to $0.5 \mathrm{mg}$. per cent. sanguinarine in plasma, the fluorescence was found to increase directly with concentration.

To extract sanguinarine from tissues, the tissue extract was made alkaline with $\mathrm{NaOH}$ and shaken with chloroform. The chloroform extract was then evaporated to dryness and the lipid taken up with benzene. Finally, the sanguinarine in the residue was dissolved in $5 \mathrm{~N} \mathrm{HCl}$.

The adsorption of sanguinarine on plasma proteins was studied using Visiking dialysis tubes and the dialysis apparatus described by Davson, Duke-Elder, and Maurice (1949). Electrophoretic studies were carried out in a solvent of 10 per cent. (w/v) formic acid at a voltage of 1,000 V and a current of 4-10 m.amp. Crystalline sanguinarine nitrate was obtained from Fluka (Switzerland). This preparation was recrystallized from hydrochloric acid to obtain the sanguinarine chloride. The final crystalline powder was compared for purity against a sample of pure sanguinarine chloride kindly supplied by Dr. J. Walker (Medical Research Council) and the results indicated that the sanguinarine used in these studies contained over 95 per cent. sanguinarine chloride.

\section{Results}

MANOMETRIC StUdiEs.-The influence of an intravenous injection of sanguinarine on the intra-ocular and femoral blood pressures of an anaesthetized cat is shown in a typical result in Fig. 2 (overleaf). At this dosage the blood and intra-ocular pressures changed synchronously and returned to normal in 5 to 10 minutes. Similar experiments were made on a total of eight cats and in each animal an intravenous injection of 2 to $6 \mathrm{mg} . / \mathrm{kg}$. caused a transient increase in the femoral and intra-ocular pressures. A lower dose of sanguinarine caused little, if any, change in pressure, while a rapid intravenous dose of more than $6 \mathrm{mg} . / \mathrm{kg}$. caused respiratory distress and an irreversible fall in both the blood and the intra-ocular pressures (Fig. 3, overleaf). In view of the possibility that the transient pressure changes were caused by the acidity of the sanguinarine solution, control experiments were made in three of the same group of cats. In these animals an intravenous injection of an equivalent amount of hydrochloric acid caused no change in the blood and intraocular pressures.

Attempts to prolong the pressure changes in cats after intravenous injections of sanguinarine were made employing a continuous infusion technique. In two cats infusions of 4 and $10 \mathrm{mg}$. $/ \mathrm{kg}$. in 10 minutes failed to modify the blood or intra-ocular pressures, while in the same animals a rapid intravenous injection of $4 \mathrm{mg} . / \mathrm{kg}$. sanguinarine gave the typical transient increase in blood and intra-ocular pressures described above. In two further cats an infusion of $4 \mathrm{mg}$. $/ \mathrm{kg}$. in 10 minutes failed to prolong the rise in pressure caused by a preliminary rapid intravenous injection of $4 \mathrm{mg} . / \mathrm{kg}$. 

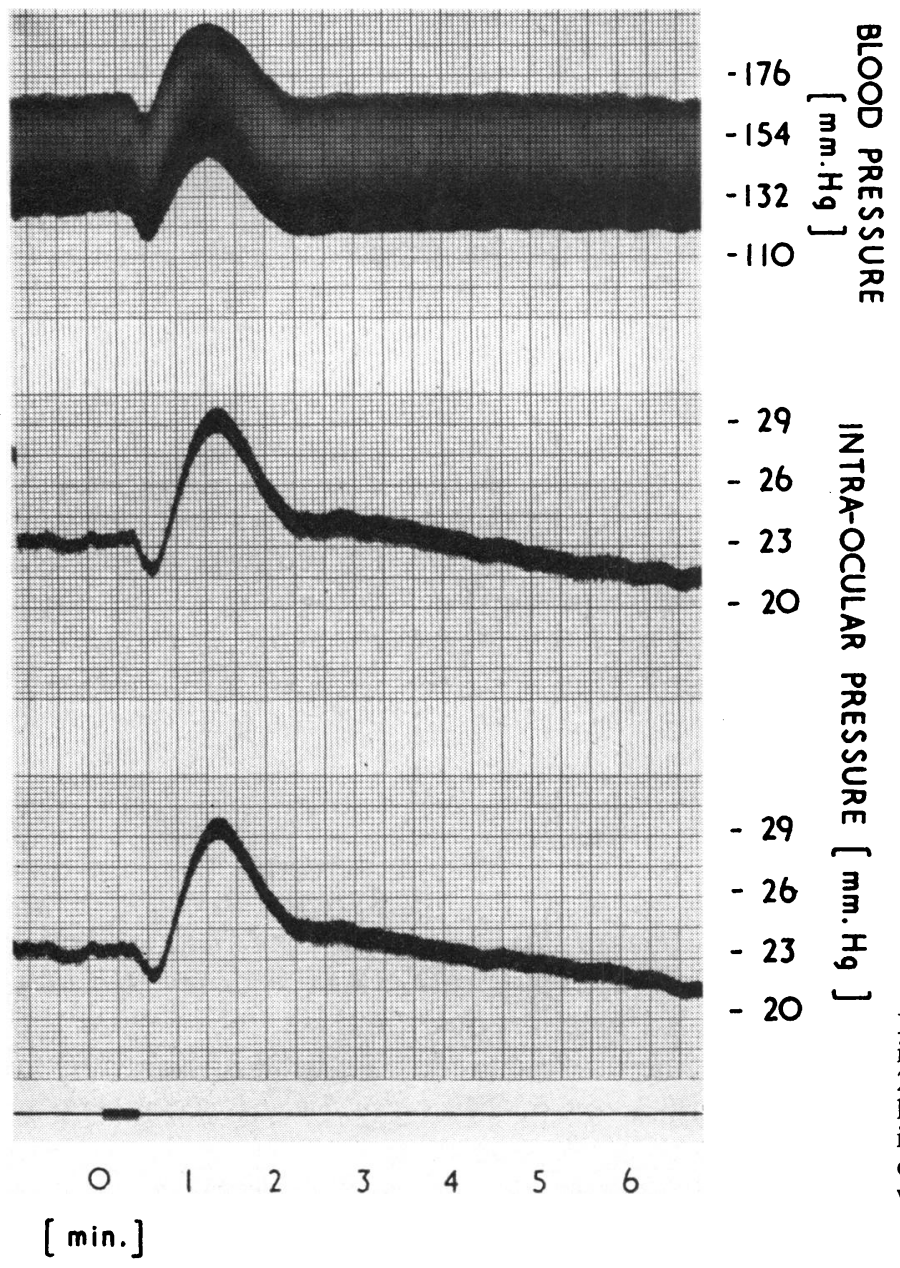

FIG. 2.-Effect of an intravenous injection of 2 mg. sanguinarine per kg. on the femoral and intra-ocular pressures of a cat anaesthetized with Urethane.

The immediate response of rabbits to intravenous injections of sanguinarine differed from that of cats (Fig. 4, overleaf). Eight rabbits were given $4 \mathrm{mg}$. $/ \mathrm{kg}$. sanguinarine intravenously and in all animals the intra-ocular pressure increased and returned to normal within 10 to 15 minutes. However, the femoral blood pressure of seven of these animals decreased concurrently with the increase in intra-ocular pressure, and in the eighth rabbit the blood pressure remained constant in spite of a rise of $15 \mathrm{~mm}$. $\mathrm{Hg}$ in the intraocular pressure. Higher doses of sanguinarine caused irreversible falls in both the blood and intra-ocular pressure. In three rabbits an infusion of $10 \mathrm{mg}$. $/ \mathrm{kg}$. given over 10 minutes failed to prolong the ocular hypertension caused by a preliminary rapid intravenous injection of $4 \mathrm{mg}$. $/ \mathrm{kg}$. sanguinarine.

In a further attempt to induce a change in the steady state intra-ocular pressure, three rabbits were injected intravenously with $4 \mathrm{mg} . / \mathrm{kg}$. sanguinarine every 30 minutes for 3 hours. At the end of this period, the animals 
Fig. 3.-Influence of an intravenous injection of $6 \mathrm{mg} . / \mathrm{kg}$. on the femoral and intra-ocular pressures of a cat (wt. $3.3 \mathrm{~kg}$.) anaesthetized with Urethane. The superior cervical ganglion of the left eye (lowest record) had been extirpated 24 hours previously.

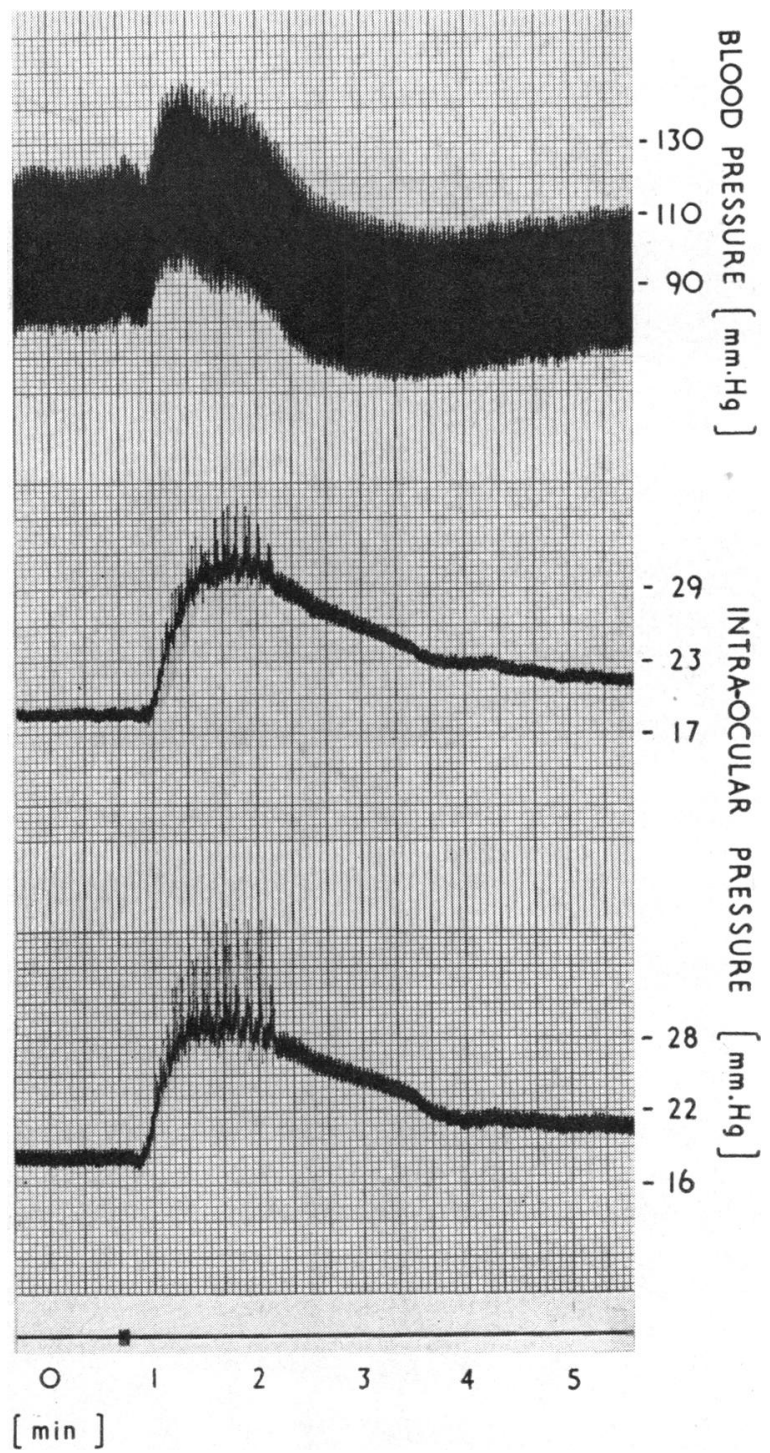

were anaesthetized with Urethane and the blood and intra-ocular pressures measured. The mean intra-ocular pressure of the six eyes was $20.5 \pm 1.2$ $\mathrm{mm}$. $\mathrm{Hg}$, and the femoral blood pressures in the three animals were 110 , 115 , and $90 \mathrm{~mm}$. $\mathrm{Hg}$. These values are not significantly different from those found in untreated rabbits measured under the same experimental conditions (Langham, 1959).

The effect of an intraventricular injection of sanguinarine on the blood and intra-ocular pressures was measured manometrically in a series of eight cats and two rabbits. In both species it required an injection of 10 

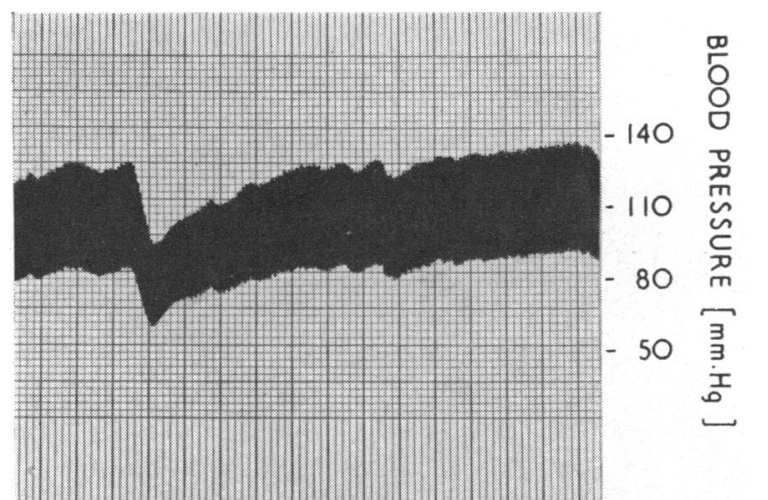

to $50 \mu \mathrm{g}$. to give a significant change in ocular pressure, whereas an intravenous injection of 1,000 to $5,000 \mu \mathrm{g}$. was required to give a similar ocular response. 10 to $50 \mu \mathrm{g}$. sanguinarine injected into the lateral ventricle of cats caused a transient increase in the blood and intra-ocular pressures; a typical result is shown in Fig. 5 (opposite). In the same animals, atropine given intravenously (1 to $2 \mathrm{mg} . / \mathrm{kg}$.) completely inhibited this response.

With intraventricular injections of 50 to $100 \mu \mathrm{g}$. sanguinarine, the effects were more prolonged. Thus, in two cats given 60 and $80 \mu \mathrm{g}$. sanguinarine respectively, the blood pressure increased from initial values of 140 and 110 $\mathrm{mm}$. $\mathrm{Hg}$ to 180 and $160 \mathrm{~mm}$. $\mathrm{Hg}$ and the hypertension was maintained until termination of the experiments 1 to 2 hours later. In the same animals, the changes in intra-ocular pressure lasted only 15 to 20 minutes. Confirmation of this transient effect on intra-ocular pressure in the presence of a sustained blood pressure rise was found in measurements of the pressure in the untouched contralateral eye 30 minutes after the injection of sanguinarine; at this time the pressures in the eyes of the two cats were normal. In a third cat, an intraventricular injection of $80 \mu \mathrm{g}$. sanguinarine caused a rapid increase in the blood pressure to well over $200 \mathrm{~mm}$. $\mathrm{Hg}$ and the animal died 5 minutes after the injection (Fig. 6, overleaf). 


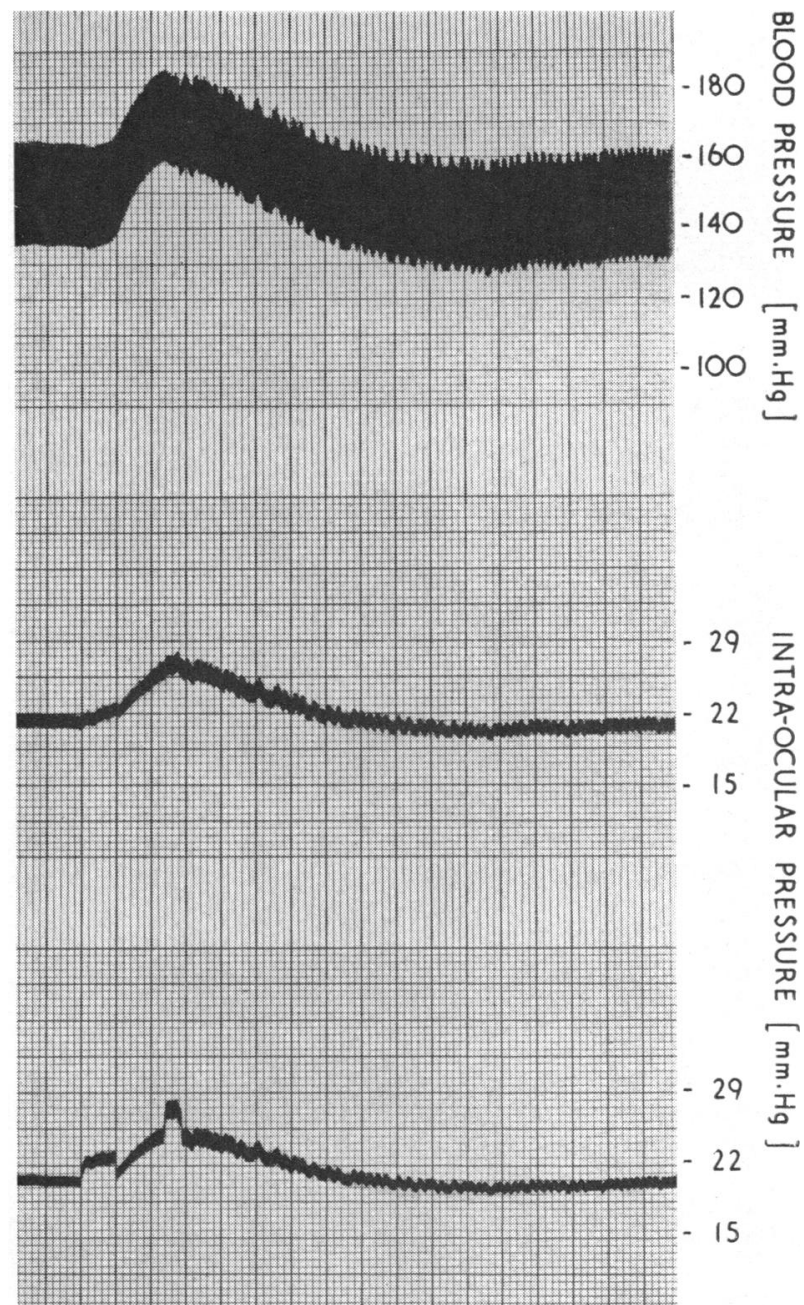

FIG. 5.-Effect of an intraventricular injection of $10 \mu \mathrm{g}$. sanguinarine on the femoral and intra-ocular pressures of a cat (wt. $2 \mathrm{~kg}$.) anaesthetized with Urethane.

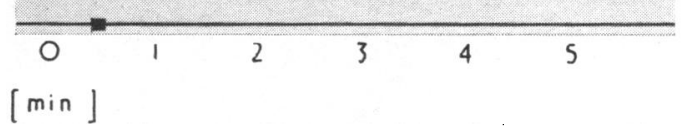

The blood and intra-ocular pressures of the two rabbits given intraventricular injections of sanguinarine reacted in a similar manner to those described for cats. Injections of $20 \mu \mathrm{g}$. caused a reversible increase in blood and intra-ocular pressures while injections of 80 and $100 \mu \mathrm{g}$. caused a sustained increase in blood pressure but only a transient increase in the intraocular pressure.

Experiments on Conscious Animals.-Ten conscious cats were injected with sanguinarine into the lateral ventricles through an indwelling cannula and from observations on these animals a characteristic pattern of response emerged. 


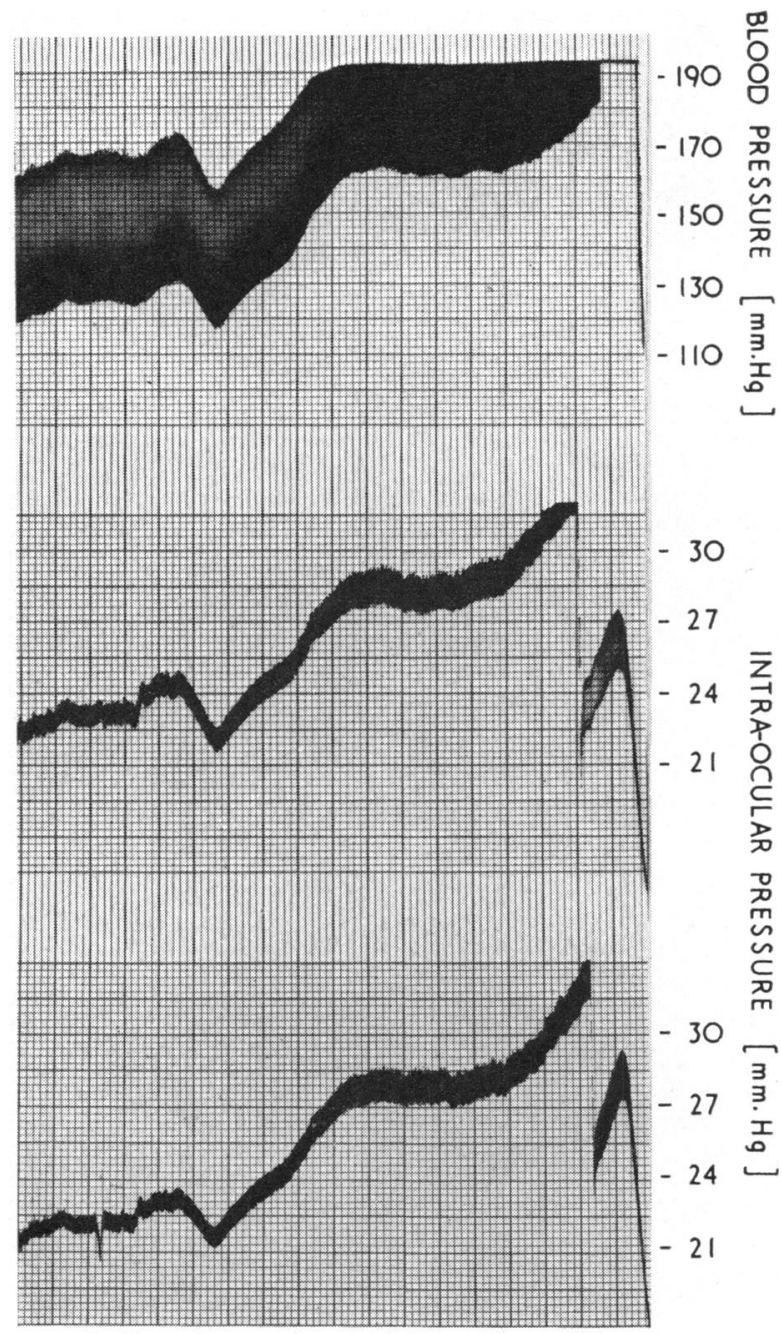

$[\min ]$
FIG. 6.-Action of $100 \mu \mathrm{g}$. sanguinarine injected into the lateral ventricle of an anaesthetized cat. The blood pressure rose to a mean value of $240 \mathrm{~mm} . \mathrm{Hg}$ and cardiac arrest took place $(5 \mathrm{~min}$. after the injection).
With small doses (10 to $30 \mu \mathrm{g}$.) there is no reaction and the cat continues to purr and play. At slightly higher doses (40 to $60 \mu \mathrm{g}$.) the cat shows an immediate reaction; within 15 seconds it stops purring, withdraws into a corner and remains disinterested in its surroundings and food for periods up to 12 hours. During this time, the cat shows no sign of being distressed but keeps its eyes half closed and has marked photophobia. Provided no further injections are made, the cat recovers completely within 24 hours. If the intraventricular injections are increased above $60 \mu \mathrm{g}$. the reactions are more severe. The pupils dilate maximally, respiration becomes shallow and rapid, the animal becomes very lethargic, and sometimes the head is held down on the same side as that of the injection.

On the basis of these acute experiments, single doses of between 30 and 
$60 \mu \mathrm{g}$. sanguinarine given periodically were used to study the chronic effects of sanguinarine on the eye. In individual animals the dosage was increased to just below the level at which marked and fatal effects occur. The results of these experiments are shown in the Table and detailed tonometric observations on some of these animals are shown in Fig. 7.

TABLE

THE EFFECT OF REPEATED INTRAVENTRICULAR INJECTIONS OF SANGUINARINE ON THE INTRA-OCULAR PRESSURE OF CONSCIOUS CATS

\begin{tabular}{c|c|c|c|c}
\hline & $\begin{array}{c}\text { Total Drug } \\
\text { (mg.) }\end{array}$ & $\begin{array}{c}\text { Time } \\
\text { (days) }\end{array}$ & \multicolumn{2}{|c}{ Intra-ocular Pressure } \\
\cline { 3 - 4 } & 680 & 16 & $7 \cdot 2 \pm 0 \cdot 4$ & $7 \cdot 6 \pm 0 \cdot 4$ \\
9095 & 1,000 & 14 & $7 \cdot 5 \pm 0 \cdot 2$ & $6 \cdot 4 \pm 0 \cdot 3$ \\
9100 & 1,020 & 18 & $7 \cdot 7 \pm 0 \cdot 1$ & $6 \cdot 9 \pm 0 \cdot 2$ \\
9127 & 520 & 17 & $7 \cdot 7 \pm 1 \cdot 0$ & $6 \cdot 3 \pm 0 \cdot 3$ \\
9129 & 510 & 20 & $6 \cdot 8 \pm 0 \cdot 4$ & $8 \cdot 3 \pm 0 \cdot 2$ \\
9240 & 740 & 40 & $7 \cdot 7 \pm 0 \cdot 2$ & $7 \cdot 6 \pm 0 \cdot 1$ \\
9278 & 460 & 30 & $5 \cdot 8 \pm 0 \cdot 1$ & $6 \cdot 3 \pm 0 \cdot 6$ \\
9330 & 240 & 13 & $6 \cdot 6 \pm 0 \cdot 4$ & $7 \cdot 0 \pm 0 \cdot 1$ \\
9331 & & & & \\
\hline
\end{tabular}

The total amount of sanguinarine (Col. 2) was given in approximately equal amounts daily over the experimental period (Col. 3). The pressure was measured with a standard Schiötz tonometer $(7.5 \mathrm{~g}$.) and the pressure readings are expressed in scale units. The initial readings represent the mean of six readings taken during the 3 days before injections of sanguinarine, and the final pressure readings represent the mean of six readings taken during the last 3 days of the experiment.

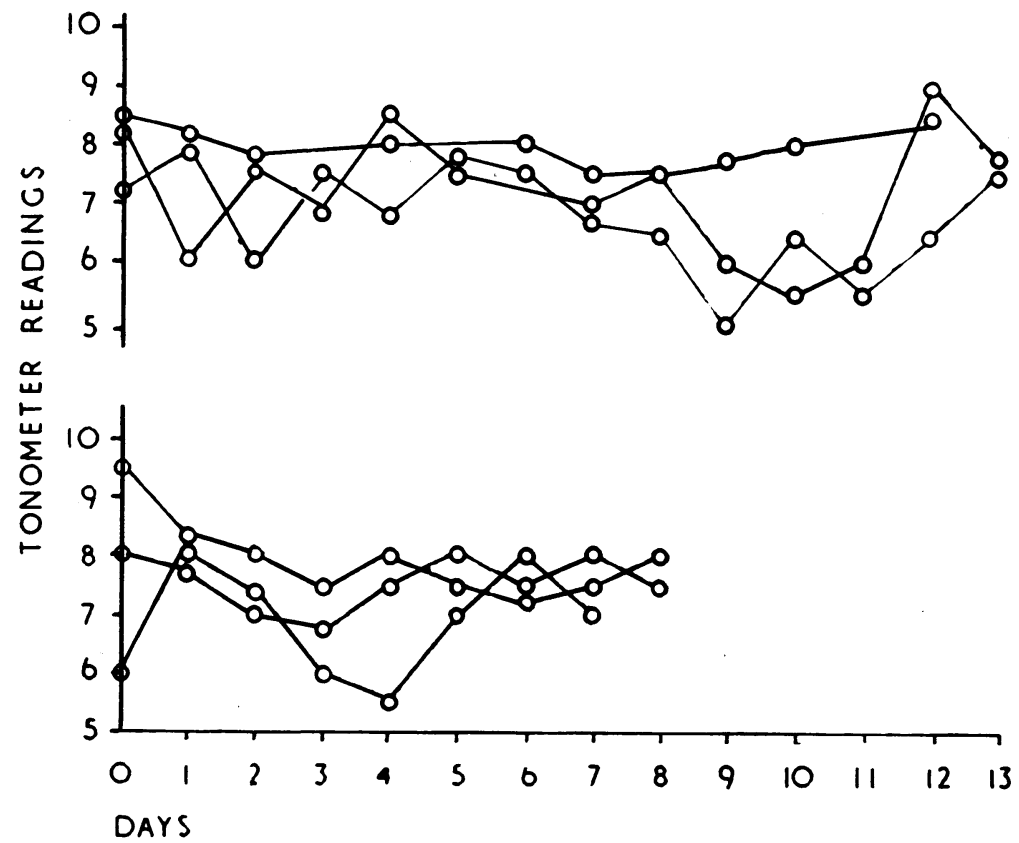

FIG. 7.-Tonometric readings taken on six cats given intraventricular injections of 30 to $50 \mu \mathrm{g}$. sanguinarine daily. 
It will be seen that no significant increase occurred in the steady state intra-ocular pressure in the eye. At the termination of the experiments, the pressures in the femoral artery and the eyes of three of these animals were determined manometrically and found to be $110,110,130$ and $20,18,22 \mathrm{~mm}$. $\mathrm{Hg}$ respectively. The eyes of the same animals were then fixed intravitally, sections of the whole eye were studied histologically, and were all found to be normal.

Feeding Experiments with Sanguinarine and Argemone oil.-Four adult rabbits were fed an average of $175 \mathrm{mg}$. sanguinarine daily for a period of 3 weeks and ocular tensions were recorded periodically with a Schiötz tonometer. All four animals remained in good health and no significant change occurred in their intra-ocular pressures. At the end of the experimental period, the intra-ocular pressures of two animals were 21 and 22.5 $\mathrm{mm}$. $\mathrm{Hg}$ measured manometrically.

Similar experiments were carried out on chickens, in view of the findings of Hart (1941) that hens fed Argemone seeds developed oedema of the wattles and combs. Four hens were given sanguinarine daily for a period of 21 to 42 days. Two hens received $1,000 \mathrm{mg}$. in 21 days and two were fed 2,390 and $2,370 \mathrm{mg}$. in 42 days. All four hens remained completely healthy, gained in body weight, and continued to lay eggs. Sanguinarine was extracted from these eggs and characterized by its emission spectrum under ultra-violet irradiation and also by its electrophoretic mobility. Hens 3 and 4 were anaesthetized at the end of the feeding experiment and the intra-ocular pressures were found to be 18 and $17 \mathrm{~mm}$. $\mathrm{Hg}$ by the manometric technique. The same animals were fixed intravitally and sections of the eye prepared for histological examination. No pathological changes were found in these eyes.

Similar feeding experiments on rabbits and hens given argemone oil were then undertaken. Three rabbits were given a total of $22 \cdot 8,48 \cdot 0$, and $38.0 \mathrm{ml}$. argemone oil over a period of 21 days. The intra-ocular pressures were measured tonometrically during the 3-week period and did not vary significantly. At the end of the 21-day period, the rabbits appeared to be in normal health and their intra-ocular pressures, measured manometrically, were found to be normal. No evidence of oedema was seen in any animal and histological examination of the eyes indicated that no pathological changes had occurred.

Four hens were given $2 \mathrm{ml}$. argemone oil daily and all showed definite reaction to the oil, starting at the 4 th to 6 th day. They appeared lethargic and this was followed in 1 to 2 days by slight to moderate oedema of the wattles and combs (Fig. 8, opposite). By this time the chickens preferred to sit down in their cages with eyes closed. Within the next 24 to 36 hours, they developed a peculiar stiff-legged gait when forced to stand and walk. At this stage the wattles were markedly oedematous and cyanotic. The chickens did not eat, and sat with their heads drooping and eyes closed. The intra-ocular 


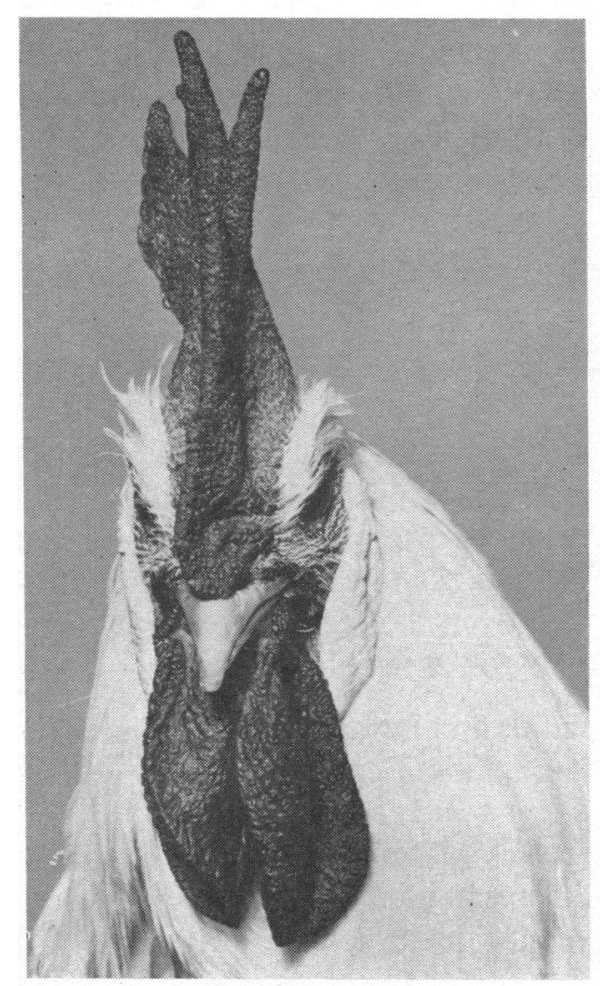

(a)

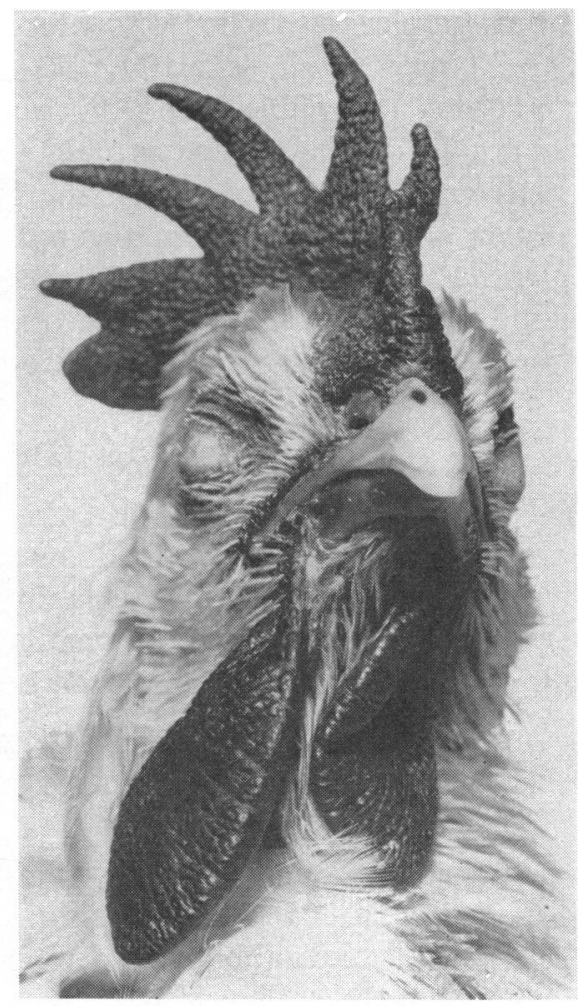

(b)

FIG. 8.-Effect of argemone oil on a chicken, (a) before, and (b) 7 days after receiving $2 \mathrm{ml}$. argemone oil daily by mouth. Note swollen wattles and photophobia.

pressures of two hens which showed marked oedema of the wattles were found to be 17 and $19 \mathrm{~mm}$. $\mathrm{Hg}$ measured manometrically. The eyes of these birds were studied histologically but no pathological changes were seen.

Chemical Studies.-Sanguinarine was found to disappear very rapidly from the plasma after an intravenous injection. No sanguinarine was detectable in the plasma 30 seconds after an intravenous injection of 4 to $20 \mathrm{mg} . / \mathrm{kg}$. The dosage of $20 \mathrm{mg} . / \mathrm{kg}$. always caused the death of a rabbit within 5 to 10 minutes and, as reported above, injections of $4 \mathrm{mg} . / \mathrm{kg}$. produced a marked transient change in the blood and intra-ocular pressures. The analytical method was sufficient to detect a concentration of $0.1 \mathrm{mg}$. sanguinarine/100 ml. of plasma.

The adsorption of sanguinarine on plasma proteins and the blood cells was studied in vitro. When plasma was dialysed against an equal volume of physiological saline containing a concentration of 1 to $20 \mathrm{mg}$. sanguinarine $/ 100 \mathrm{ml}$., the plasma proteins were found to adsorb over 95 per cent of 
the sanguinarine. When whole blood was dialysed against saline containing 1 to $20 \mathrm{mg}$. sanguinarine $/ 100 \mathrm{ml}$., the sanguinarine again passed into the sac containing the whole blood, but under these conditions, sanguinarine was not found on the plasma protein. This result indicated that sanguinarine is preferentially adsorbed on the blood cells. An attempt was made to recover sanguinarine from the red cells by the extraction procedure, but quantitative analysis of the extract was complicated by the presence of the blood pigments. The presence of sanguinarine in the red cells was, however, demonstrated by electrophoresis of the acid extract.

\section{Discussion}

These results fail to support the contention of recent investigators that sanguinarine or argemone oil may be used to produce a chronic ocular hypertension in animals. Furthermore, the results indicate that sanguinarine is not responsible for the oedema developed from the ingestion of argemone oil. These conclusions are based principally on three observations:

(a) That the immediate effect of intravenous and intraventricular injections of sanguinarine on the intra-ocular pressure of cats and rabbits was of a transient nature;

(b) that repeated intraventricular injections of sanguinarine in cats and repeated oral administration of either sanguinarine or argemone oil to cats and rabbits failed to cause a sustained increase in intra-ocular pressure;

(c) that argemone oil but not sanguinarine produced oedematous and general toxic changes in chickens.

A change in the steady state intra-ocular pressure in the eye may be brought about by an alteration in either the rate of formation or the resistance to outflow of the aqueous humour; a transient pressure change may be due to the extra-ocular muscle tone or the intra-ocular blood volume. In the latter case, alterations in pressure will be readily compensated for by a reciprocal change in the volume of the aqueous humour. The pressure changes induced by administration of sanguinarine were of a transient nature and all attempts to produce a prolonged effect failed. This was true even when an injection of sanguinarine caused a prolonged increase in the blood pressure; under these conditions the intra-ocular pressure increased concurrently with the femoral arterial pressure but returned to normal within 15 to 20 minutes.

The immediate influence of an intravenous injection of sanguinarine on the intra-ocular pressure of rabbits could not always be ascribed to a change in the systemic blood pressure. However, under these conditions, the intraocular pressure in the eye rapidly returned to normal and all attempts to produce a steady state pressure change failed. 
The observations that repeated intraventricular injections of sanguinarine in conscious cats did not induce a sustained rise in intra-ocular pressure are in contradiction to the claim of Hakim (1957). No reason, however, can be given for this discrepancy as no detailed report of his study has yet been published. In his communication, Hakim pointed out that the intraventricular route was approximately 100 times more effective than the intravenous route in producing an increase in intra-ocular pressure and he considered this to indicate the effect of central nervous activity on the equilibrium pressure of the eye. These observations have been confirmed but, as stated above, no steady state pressure change in the eye was observed under these conditions.

A chronic increase in the intra-ocular pressure of animals given either sanguinarine or argemone oil has been reported by Hakim (1954, 1957), Leach and Lloyd (1956), and Shevalev (1957). Hakim (1957) obtained the response in rabbits by daily subconjunctival injections of sanguinarine but, in view of the marked acidity of sanguinarine and its irritative properties, the observation has questionable physiological significance. Leach and Lloyd (1956) reported that monkeys fed $8 \mathrm{mg}$. sanguinarine daily over a period of 7 to 18 months developed a significant increase in intra-ocular pressure. No changes in the optic disc of these animals were seen and it was reported that intra-ocular pressure in these animals could be brought back to normal within 15 minutes by the local application of pilocarpine. Withdrawal of the alkaloid resulted in a return of the pressure to normal in 3 to 5 weeks. Shevalev (1957) measured tonometrically increases of 5 to 15 $\mathrm{mm}$. $\mathrm{Hg}$ in the intra-ocular pressure of cats injected with argemone oil, but no pathological changes were demonstrable in these eyes.

The results of the comparative activity of sanguinarine and argemone oil on chickens are considered strongly to suggest that sanguinarine is not the alkaloid responsible for the oedema developed from the ingestion of argemone oil. Sanguinarine proved to be surprisingly non-toxic to these animals, and intakes of $2,400 \mathrm{mg}$. over a period of 42 days caused no apparent impairment of health. On the other hand, $2 \mathrm{ml}$. argemone oil given daily caused marked tissue oedema and general toxic reactions within 5 days. Sarkar (1948) reported that argemone oil contained two principal alkaloids, sanguinarine and dihydrosanguinarine, and that the latter formed approximately 90 per cent of the total alkaloid content. It would therefore be of interest to know whether dihydrosanguinarine rather than its oxidized product, sanguinarine, is biologically the more active of the two.

The reaction of the human body to argemone oil became of importance with the evidence of Lal and Roy (1937) and Lal, Mukherji, Das Gupta, and Chatterji (1940) that the disease, epidemic dropsy, was caused by the ingestion of mustard seed oil contaminated with argemone oil. Their findings have been confirmed by other investigators (Steyn, 1950; Meaker, 1951) and direct observations on the toxicity of argemone oil on human volunteers 
have been described by Chopra, Pasricha, Goyal, Lal, and Sen (1939) and $\mathrm{Lal}$ and others (1941). In these studies, volunteers fed 40 to $50 \mathrm{oz}$. argemone oil over a 30-day period were found to develop oedema and typical signs of epidemic dropsy. The patients recovered within 4 to 5 days after withdrawal of the oil.

An association of glaucoma with epidemic dropsy has been reported by several investigators, but detailed supporting clinical evidence is difficult to find. Maynard (1909) and Kirwan $(1934,1936)$ reported that outbreaks of epidemic dropsy were accompanied by numerous cases of glaucoma, and Dutt (1950) stated that the incidence of glaucoma in people with epidemic dropsy varied from 2 to 30 per cent.; unfortunately, no statistics were given in these papers. Kirwan $(1934,1936)$ concluded that the glaucomatous eyes were characterized by a very high intra-ocular pressure, a deep anterior chamber, and corneal oedema. Histological examination of these eyes revealed that there was a gross dilatation of the choroidal capillaries. Kirwan (1936) also reported detailed case histories of twelve patients with glaucoma associated with epidemic dropsy. At the time of the eye examination, the patients showed no definite signs of dropsy although slight oedema of the legs was observed in five and a history of epidemic dropsy in six. The intra-ocular pressures were in the range of 40 to $60 \mathrm{~mm}$. $\mathrm{Hg}$, and were brought under control by trephine operations. At the time his paper was written, the relationship between epidemic dropsy and argemone oil had not been generally accepted, and it is therefore difficult to evaluate from the evidence presented therein whether the glaucoma was dependent on the ingestion of the oil. In this connexion, it is of interest that in the two series of volunteers fed argemone oil no glaucomatous changes were observed in spite of the oedema (Lal and others, 1941). Similarly, in the present study there was no increase in the intra-ocular pressure in the eyes of hens, rabbits or cats fed argemone oil.

\section{Summary}

(1) A study has been made of the reaction of rabbit, cat, and chicken eyes to sanguinarine given by mouth, intravenously, or intraventricularly, and to argemone oil fed to chickens and cats.

(2) In acute manometric studies, intravenous and intraventricular injections of sanguinarine were found to cause transient but no steady state increase in the intra-ocular pressure in rabbits and cats. In cats, the transient pressure changes have been ascribed to similar changes in the systemic blood pressure.

(3) Feeding or intraventricular injections of sanguinarine to rabbits, cats, and hens for periods up to 42 days caused no change in intra-ocular pressure and no histological changes in the eyes.

(4) Feeding argemone oil to hens caused oedema of the wattles and combs within 5 days. 
(5) It is concluded that sanguinarine produces only transient changes in intra-ocular pressure and has no effect on the steady state fluid dynamics of the eye. Furthermore, it is believed that sanguinarine is not the alkaloid responsible for the tissue oedema produced in hens fed argemone seeds or oil.

We wish to thank Sir Stewart Duke-Elder for his interest in this work and the Medical Research Council for defraying the cost of this study. This work was also supported by a Special Traineeship BT-416(Cl) to G. C. Dobbie from the National Institute of Neurological Diseases and Blindness of the U.S. Public Health Service.

\section{REFERENCES}

Chopra, R. N., Pasricha, C. L., Goyal, R. K., Lal, S., and Sen, A. K. (1939). Indian med. Gaz., 74, 193.

Davson, H., Duke-Elder, S., and Maurice, D. M. (1949). J. Physiol. (Lond.), 109, 32.

DuTT, S. C. (1950). XVI Concilium Ophthalmologicum, Britannia Acta, 1950, vol. 2, p. 872. B.M.A., London.

Feldberg, W., and SHerwood, S. L. (1953). J. Physiol. (Lond.), 120,.3P.

HAKIM, S. A. E. (1954). Brit. J. Ophthal., 38, 193. (1957). J. Physiol. (Lond.), 138, 40P.

HART, L. (1941). Aust. vet. J., 17, 69.

KIRWAN, E. W. O'G. (1934). Arch. Ophthal. (Chicago), 12, 1. (1936). Brit. J. Ophthal., 20, 321.

Lal, R. B., Das Gupta, A. C., Mukherji, S. P., and Adak, B. (1941). Indian J. med. Res., 29, 839.

, Mukherj, S. P., Das Gupta, A. C., and Chatterji, S. R. (1940). Ibid., 28, 163. and RoY, S. C. (1937). Ibid., 25, 233.

LANGHAM, M. E. (1959). Brit. J. Ophthal., 43, 705.

LEACH, E. H., and LloYd, J. P. F. (1956). Trans. ophthal. Soc. U.K., 76, 453.

LIEB, W. A., and SCHERF, H.-J. (1956). Klin. Mbl. Augenheilk., 128, 686.

MAYNARD, F. P. (1909). Indian med. Gaz., 44, 373.

MEAKER, R. E. (1951). S. Afr. med. J., 24, 331.

SARKAR, S. N. (1948). Nature (Lond.), 162, 265.

Shevalev, A. E. (1957). "Bengal Glaucoma". Odessa.

STEYN, D. G. (1950). S. Afr. med. J., 24, 333. 